Note

\section{Isolation and Identification of Aucuparin as a Phytoalexin from Eriobotrya japonica L.}

\author{
Keisuke Watanabe, Yukio Ishiguri, \\ Fukuji NonAKA* and Akira Morita** \\ Pesticide Research Department, \\ Institute for Biological Science, \\ Sumitomo Chemical Co., Ltd., \\ Takatsukasa, Takarazuka, Hyogo 665, Japan \\ *Faculty of Agriculture, Saga University, \\ Honjo, Saga 840, Japan \\ **Nagasaki Fruit-Tree Experiment Station, \\ Onihashi, Ohmura, Nagasaki 856-01, Japan
}

Received July 16, 1981

Previously, we reported on the production of a phytoalexin in the cortical layer of the loquat shoot (Eriobotrya japonica L.) when it was inoculated with Colletotrichum lindemuthianum. ${ }^{1)}$ In this communication, isolation and identification of the phytoalexin are described. The antimicrobial properties of the phytoalexin are also briefly mentioned.

The cortical layer of a loquat shoot $(4 \mathrm{~kg}, 3 \mathrm{~cm}$ in length, each) was pealed off and the inoculum droplets $(0.3 \sim 0.6 \mathrm{ml}$, each) containing spores of $C$. lindemuthianum were put on each cortical layer. After incubation at $25^{\circ} \mathrm{C}$ for $24 \mathrm{hr}$, the droplets were collected and centrifuged at $14,000 \mathrm{rpm}$ for $20 \mathrm{~min}$. The supernatant layer was adjusted to $\mathrm{pH} 3$ with $\mathrm{HCl}$ and extracted with petroleum ether. On evaporation of the solvent, $35 \mathrm{mg}$ of crude antimicrobial material was obtained. A TLC (Merck Kieselgel $60 \mathrm{GF}_{254}$, $0.25 \mathrm{~mm}$ ) analysis of the crude material developed with $n$ hexane-ethyl acetate-methanol $(60: 40: 1 \mathrm{v} / \mathrm{v})$, indicated the presence of one major spot at $R f 0.62 \sim 0.65$ when viewed under UV light $(254 \mathrm{~nm})$. The major spot was not detected in the corresponding extract of a healthy cortical layer. ${ }^{2)}$ A TLC bioautography of the same material against Cochiobolus miyabeanus revealed that the above spot was antimicrobial. The crude material was purified on TLC plates to give the pure compound (I) $2.0 \mathrm{mg}, \mathrm{mp}$ $101 \sim 101.5^{\circ} \mathrm{C}$. The mass spectrum of I gave a molecular ion peak at $\mathrm{m} / z 230(100 \%)$, corresponding to $\mathrm{C}_{14} \mathrm{H}_{14} \mathrm{O}_{3}$ and fragments at $215\left(\mathrm{M}^{+}-\mathrm{CH}_{3}, 25 \%\right), 187$ $\left(\mathrm{M}^{+}-\mathrm{CH}_{3}-\mathrm{CO}, 25 \%\right)$ : $\mathrm{UV} \lambda{ }_{\max }^{\mathrm{EtOH}} \mathrm{nm}(\log \varepsilon) 273(4.18)$ and IR $v^{\text {nujol }} \mathrm{cm}^{-1}: 3420,1610,1380,1340,1120$. In its PMR spectrum, I showed a multiplet of mono substituted phenyl ring protons at $\delta{ }_{\mathrm{TMS}}^{\mathrm{CDCl}_{3}} 7.30(5 \mathrm{H})$ and a singlet at $\delta 3.85(6 \mathrm{H})$ due to two methoxy groups. A broad singlet at $\delta 5.30(1 \mathrm{H})$ indicated the presence of one hydroxyl group in the molecule, supported by the IR spectrum. In its UV spectrum, the absorption at $273 \mathrm{~nm}$ was diagnostic for a biphenyl system with bathochromic substituents on 3,4 and 5 positions in one phenyl ring. ${ }^{3)}$ Equivalence of the two methoxy groups whose PMR signal appeared as a 6 proton singlet at $\delta 3.85$ indicated that the whole molecule should be symmetrically substituted. On the basis of the above spectroscopic data, it was reasonably predicted that the phytoalexin seemed to be aucuparin (I) (4-hydroxy3,5-dimethoxybiphenyl), originally isolated from the

Table I. Antimicrobial Activities of Natural and Synthetic Aucuparin

(I) AGAINST Colletotrichum lindemuthianum AND Pestalotia funerea

(24 and $48 \mathrm{hr}$ after inoculation)

\begin{tabular}{|c|c|c|c|c|c|c|c|c|c|}
\hline \multirow{3}{*}{ Fungi } & \multirow{3}{*}{$\begin{array}{l}\text { Aucuparin } \\
\text { conc. }(\mathrm{ppm})^{a}\end{array}$} & \multicolumn{4}{|c|}{ Germination rate $(\%)^{b}$} & \multicolumn{4}{|c|}{ Germ tube length $(\mu \mathrm{m})^{c}$} \\
\hline & & \multicolumn{2}{|c|}{ Natural } & \multicolumn{2}{|c|}{ Synthetic } & \multicolumn{2}{|c|}{ Natural } & \multicolumn{2}{|c|}{ Synthetic } \\
\hline & & $24 \mathrm{hr}$ & $48 \mathrm{hr}$ & $24 \mathrm{hr}$ & $48 \mathrm{hr}$ & $24 \mathrm{hr}$ & $48 \mathrm{hr}$ & $24 \mathrm{hr}$ & $48 \mathrm{hr}$ \\
\hline \multirow{4}{*}{$\begin{array}{l}\text { C. lindemuthianum } \\
\text { (non-phytopathogenic) }\end{array}$} & $0^{*}$ & 90 & 100 & 89 & 99 & 500 & 500 & 500 & 500 \\
\hline & 10 & 38 & 42 & 41 & 41 & 24 & 29 & 31 & 31 \\
\hline & 50 & 5 & 6 & 3 & 4 & 8 & 9 & 5 & 5 \\
\hline & 100 & - & - & 0 & 0 & - & - & 0 & 0 \\
\hline \multirow{4}{*}{$\begin{array}{l}\text { P. funerea } \\
\text { (phytopathogenic) }\end{array}$} & $0^{*}$ & 97 & 100 & 93 & 100 & 252 & 500 & 210 & 500 \\
\hline & 10 & 72 & 100 & 76 & 100 & 75 & 213 & 80 & 220 \\
\hline & 50 & 63 & 85 & 60 & 88 & 72 & 185 & 69 & 180 \\
\hline & 100 & - & - & 30 & 66 & - & - & 5 & 60 \\
\hline
\end{tabular}

a In water-ethanol $(98: 2, \mathrm{v} / \mathrm{v})$.

$b 60$ spores were counted.

Mean length of germ tubes of 50 spores selected from 600 spores in sequence of their germ tube length.

* Blank (treated with $2 \%$ ethanol only). 
healthy heartwood of Sorbus aucuparia. ${ }^{4)}$ The phytoalexin from the cortical layer was identical in all respects (PMR, UV, MS and GLC $t_{\mathrm{R}}$ ) with a synthetic specimen prepared by the authors according to the reported procedures. ${ }^{5)}$ Since the natural phytoalexin was isolated in a small quantity, the antimicrobial properties of the synthetic aucuparin were studied in comparison with the natural specimen.

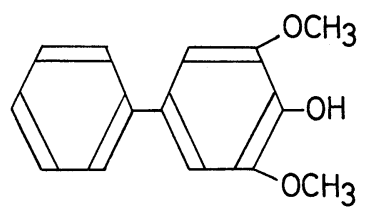

FIG. 1. The Structure of Aucuparin (I).

The natural and synthetic aucuparin (I) revealed similar activities against Colletotrichum lindemuthianum, a nonphytopathogenic fungus for loquat, and Pestalotia funerea, a phytopathogenic fungus of loquat gray leaf spot (see Table I). Spore germination of $C$. lindemuthianum was more severely inhibited by $50 \mathrm{ppm}$ of aucuparin (I) than that of $P$. funerea at $24 \mathrm{hr}$ after inoculation. Then, after $48 \mathrm{hr}$, the germ tube growth of $P$. funerea recovered significantly, indicating that aucuparin was probably in- activated by $P$. funerea. The recovery and insensitivity of $P$. funerea to aucuparin would account for the phytopathogenic character of the fungus against loquat.

Although a number of phytoalexins have been isolated from various kinds of plants, no phytoalexins of the biphenyl type have been reported so far. This is the first report of the isolation of the substituted biphenyl, aucuparin (I), as the phytoalexin of the cortical layer of loquat shoot. A TLC bioassay of the extract indicated the presence of other minor components of the phytoalexins which are the subject of further investigations.

\section{REFERENCES}

1) A. Morita, F. Nonaka and K. Makisumi, Ann. Phytopath. Soc. Jpn., 46, 386 (1980).

2) A. Morita, Proc. Assoc. Pl. Prot. Kyushu, 25, 165 (1976).

3) A. I. Scott, "Interpretation of the Ultraviolet Spectra of Natural Product," Pergamon Press Ltd., London, 1964 , pp. $89 \sim 134$.

4) H. Erdtman, G. Eriksson and T. Norin, Acta Chem. Scand., 15, 1796 (1961).

5) M. Nilson and T. Norin, Acta Chem. Scand., 17, 1157 (1963). 